\title{
Improvements in the lifestyle of patients who have had type 1 diabetes for 50 years: an optimistic message
}

\author{
J.-J. Altman • C. Vincent-Cassy $\cdot$ S. Feldman-Billard
}

Received: 15 August 2008 / Accepted: 24 October 2008 / Published online: 26 November 2008

(C) Springer-Verlag 2008

Keywords Chronic disease - Quality of life - Type 1 diabetes

To the Editor: The life expectancy of patients with type 1 diabetes continues to improve. Better care has reduced the frequency of organic complications and improved their management. But what is the impact upon quality of life? Two studies, the UK Golden Years cohort [1] and the 50 year Joslin Medalist study [2], have examined the clinical characteristics of type 1 diabetic patients with long disease duration. Here we describe a Parisian cohort and evaluate the lifestyle of patients suffering from this chronic disease for 50 years.

Investigators (J.-J. Altman, S. Feldman-Billard) at two centres followed 57 patients with a mean duration of type 1 diabetes of $49.8 \pm 7.6$ years on an outpatient basis over several decades. Standard clinical data, common laboratory tests and regular screening for chronic complications were recorded, as well as markers of metabolic control and diabetes treatment (Table 1). All patients gave informed consent and completed a quality of life questionnaire during a routine visit. The main items on the questionnaire were marital status with description of offspring, physical

J.-J. Altman $(\bowtie) \cdot$ C. Vincent-Cassy

Service de Diabétologie, Hôpital Européen Georges Pompidou,

20 rue Leblanc,

75908 Paris Cedex 15, France

e-mail: jean-jacques.altman@egp.aphp.fr

J.-J. Altman

Université René Descartes,

Paris, France

S. Feldman-Billard

Service de Médecine Interne, CHNO des Quinze-Vingts,

Paris, France activity and social life (cultural, training, travelling, sexual activity). Data concerning professional life included: educational level, professional activity, retirement, working days missed because of the disease and impact on professional life. The patients were also asked to classify the burdens impairing their life, to evaluate the main improvements in the treatment of the disease during their lifetime and to specify the most helpful person/organisation in their life (see text box). Statistical analysis was performed with the SPSS statistical software version 14.0 for Windows (SPSS, Chicago, IL, USA). The variables presented were summarised as means $\pm \mathrm{SD}$.

Mean systolic and diastolic blood pressure was $137.4 \pm$ 22.9 and $78.4 \pm 9.5 \mathrm{mmHg}$, respectively. Treatment and monitoring followed the rules of intensified therapy, but mean $\mathrm{HbA}_{1 \mathrm{c}}$ was $8.6 \pm 1.3 \%$; only $10 \%$ of patients had an $\mathrm{HbA}_{1 \mathrm{c}}$ value below 7\%. Mean HDL-cholesterol was higher than $1.25 \mathrm{mmol} / 1$ in $86 \%$ of patients. Poor vision, with visual acuity $<20 / 200$, was present in $19 \%$ of the patients, with a similar number having serum creatinine above $120 \mu \mathrm{mol} / 1$. Only one patient had no evidence of diabetic retinopathy [3] and five were blind. Three others had functioning kidney grafts, combined with a pancreas graft in one case. Two were on regular haemodialysis.

Some $81 \%$ of patients had married and $9 \%$ were divorced; $84 \%$ of patients had at least one child. On average, they had $1.40 \pm 1.23$ (range $0-4$ ) children and 1.24 \pm 1.96 (0-7) grandchildren, with no difference between men and women. Only five men and four women had no children. All but two were independent. Physical activity of more than $30 \mathrm{~min}$ per day was reported by $86 \%$ and gardening by $25 \%$. Social life was rated as being impaired by $54 \%$, but nearly all patients went regularly to the cinema $(93 \%)$, theatre $(81 \%)$ or restaurants $(91 \%)$. Half engaged in 


\begin{tabular}{|c|c|c|}
\hline \multicolumn{3}{|c|}{ List of burdens and improvements in the treatment of diabetes } \\
\hline Burdens & Improvements & Help from other people \\
\hline SMBG (1) & Early detection of complications $(1)^{\mathrm{a}}$ & Spouse (1) \\
\hline Diet (2) & Laser therapy $(1)^{\mathrm{a}}$ & Diabetologist (2) \\
\hline Visual impairment (3) & Self-monitoring of blood glucose (3) & General practitioner ( 3 ) \\
\hline Insulin injections (4) & Insulin pens and disposable equipment (4) & Parents \\
\hline SMURG & Premix insulins & Psychologist/psychiatrist \\
\hline Kinetic impairment & Educational programme & Other diabetic patients \\
\hline Limitations of physical activity & Liberalisation of diet & Associative organisation \\
\hline Difficulties when going out & Interest in mental status of patient & \\
\hline Hypoglycaemia & Help from associative organisation & \\
\hline Pregnancy management & Normal pregnancy outcome & \\
\hline Impairment of sexual life & Accessibility of contraceptive method & \\
\hline \multicolumn{3}{|l|}{ Impairment of professional life } \\
\hline \multicolumn{3}{|l|}{ Risk of depression } \\
\hline Familial relationship alteration & & \\
\hline
\end{tabular}

sport on a regular basis, and $60 \%$ made use of public transport; the same proportion travelled regularly, mostly abroad. Regular sexual activity was reported in the past by $81 \%$ and was current in $60 \%$. Educationally, $60 \%$ had a university degree; all but three patients were employed ( $90 \%$ full time), none had asked for early retirement and $40 \%$ were still working at the time of the study. Fifty-four per cent had never missed work because of diabetes, although half considered that the condition had restricted their professional activity.

The most frequently reported burdens were the need to self-monitor blood glucose, the need for perpetual diet, visual impairment and insulin injections. The four most popular improvements were the use of laser therapy in the management of chronic complications, followed by glucose monitoring, insulin pens and disposable equipment. In order of importance, the most helpful persons in their life were their spouse, their diabetologist and their general practitioner (see text box).

A quarter of a century ago, the life expectancy of a 25-year-old type 1 diabetic patient, was 33 years [4]. Our patients had a mean period of 35 years free from significant complications impairing their life. Our type 1 diabetic Parisian cohort resembled the Golden Years cohort [1].
Macroangiopathy was rarely present, because of, at least in part, a favourable cholesterol ratio [5]. In the 50 year Medalist study, HDL-cholesterol was high and mean $\mathrm{HbA}_{1 \mathrm{c}}$ was elevated as in our group, but close to half did not report any significant microvascular complications [2]. The Medalist study also reported a lack of association between glycaemic control and the prevalence of such complications [2]. The low dose of insulin needed was comparable to ours. The authors of the above two studies [1,2] speculate that their patients could possibly be protected by a favourable genetic background. Fertility was initially described as reduced in type 1 diabetic women but normalisation has occurred in more recent cases [6]. It is notable that in our cohort the fertility ratio was the same in women as in men.

All our patients were followed by the same practitioners for decades and the questionnaires were completed after about 50 years of diabetes. In other studies, quality of life questionnaires were mainly addressed to patients with a rather shorter duration of diabetes [7, 8]. It is not possible to compare our cohort with non-surviving patients selected by the time and age of diagnosis. Comparison with type 2 diabetic patients is not relevant. Of course, our cohort was selected by life, environment, socio-cultural status, genes and metabolism, as well as many other possibilities. We 
Table 1 Characteristics of the 57 patients of the Parisian Cohort

\begin{tabular}{|c|c|}
\hline Characteristic & $\begin{array}{l}\text { Mean } \pm \text { SD } \\
\text { or } \%\end{array}$ \\
\hline Diabetes duration (years) & $49.8 \pm 7.6$ \\
\hline Male patients & 47 \\
\hline Age (years) & $67.1 \pm 10.8$ \\
\hline Age at diagnosis of diabetes (years) & $17.3 \pm 9.3$ \\
\hline Patients with BMI $<25 \mathrm{~kg} / \mathrm{m}^{2}$ & 67 \\
\hline $\mathrm{HbA}_{1 \mathrm{c}}(\%)$ & $8.6 \pm 1.3$ \\
\hline Patients with $\mathrm{HbA}_{1 \mathrm{c}}<7 \%(\%)$ & 10 \\
\hline Insulin dosage (IU kg ${ }^{-1}$ day $^{-1}$ ) & $0.52 \pm 0.20$ \\
\hline Patients with insulin dosage $<0.3 \mathrm{IU} \mathrm{kg}^{-1}$ day $^{-1}(\%)$ & 19 \\
\hline Patients with three to five insulin injections per day (\%) & 60 \\
\hline $\begin{array}{l}\text { Patients self-monitoring blood glucose more than } \\
\text { once a day }(\%)\end{array}$ & 97 \\
\hline Systolic blood pressure $(\mathrm{mmHg})$ & $137.4 \pm 22.9$ \\
\hline Diastolic blood pressure (mmHg) & $78.4 \pm 9.5$ \\
\hline $\begin{array}{l}\text { Patients with blood pressure }<40 / 80 \mathrm{mmHg} \text { without } \\
\text { treatment }\end{array}$ & 19 \\
\hline Patients with LDL-cholesterol $<3.30 \mathrm{mmol} / 1$ & 82 \\
\hline Patients with HDL-cholesterol $>1.25 \mathrm{mmol} / \mathrm{l}$ & 86 \\
\hline $\begin{array}{l}\text { Patients with no retinopathy or non-proliferative } \\
\text { retinopathy }\end{array}$ & 19 \\
\hline Patients with severe non-proliferative retinopathy & 21 \\
\hline Patients with proliferative retinopathy & 60 \\
\hline Patients with photocoagulation & 79 \\
\hline Patients with macular oedema & 35 \\
\hline Patients with low vision & 19 \\
\hline Patients with cataract surgery & 96 \\
\hline Patients with serum creatinine $>120 \mu \mathrm{mol} / 1$ & 19 \\
\hline Patients with micro- or macroalbuminuria & 32 \\
\hline Patients with at least one child & 84 \\
\hline \multicolumn{2}{|l|}{ Number of children } \\
\hline Men and women combined & $1.40 \pm 1.23$ \\
\hline Men only & $1.53 \pm 1.39$ \\
\hline Women only & $1.30 \pm 1.11$ \\
\hline Patients with at least one grandchild & 37 \\
\hline Number of grandchildren & $1.24 \pm 1.96$ \\
\hline
\end{tabular}

have no way of demonstrating which of these factors is the most prominent. This important problem was not the focus of our study. Importantly, for whatever reason, we have been able to show that a rather large cohort of patients with type 1 diabetes, a previously fatal disease, were able to enjoy familial, professional and socio-cultural success. For diabetic patients, who spend so much time and effort coping with their disease, this is a truly optimistic message.

Duality of interest The authors declare that there is no duality of interest associated with this manuscript.

\section{References}

1. Bain SC, Gill GV, Dyer PH et al (2003) Characteristics of type 1 diabetes of over 50 years duration (the Golden Years Cohort). Diabet Med 20:808-811

2. Keenan HA, Costacou T, Sun JK et al (2007) Clinical factors associated with resistance to microvascular complications in diabetic patients of extreme disease duration: the 50-year Medalist study. Diabetes Care 30:1995-1997

3. Feldman-Billard S, Limon S, Morin Y, Altman JJ (2001) Type 1 diabetes with no diabetic complications, sixty two years later. J Diabetes Complications 15:285-286

4. Anderson RM (1991) The challenge of translating scientific knowledge into improved diabetes care in the 1990s. Diabetes Care 14:418-421

5. Qasim A, Rader DJ (2006) Human genetics of variation in highdensity lipoprotein cholesterol. Curr Atheroscler Rep 8:198-205

6. Jonasson JM, Brismar K, Sparén P et al (2007) Fertility in women with type 1 diabetes: a population-based cohort study in Sweden. Diabetes Care 30:2271-2276

7. EDIC Research Group (1999) Epidemiology of Diabetes Interventions and Complications (EDIC). Design, implementation, and preliminary results of a long-term follow-up of the Diabetes Control and Complications Trial cohort. Diabetes Care 22:99-111

8. Gafvels C, Lithner F, Börjeson B (1993) Living with diabetes: relationship to gender, duration and complications. A survey in northern Sweden. Diabet Med 10:768-773 